\title{
The Influence of Organization Climate Support for Innovation on Project Sustainability
}

\author{
Amara M. Kamara ${ }^{1}$ and Dr. CathlynnD'silva $(\mathbf{P h D})^{2}$ \\ ${ }^{1}$ School of Postgraduate Studies, University of Kigali, Rwanda \\ ${ }^{2}$ University of Kigali, Rwanda
}

\begin{abstract}
The research focused on the analysis of the influence of Organization Climate Support for Innovation on Project Sustainability. Descriptiveand regression researchtechnique was adopted. The target population was 160 employees from Serena and Marriott Hotels, and its sample size was 113 using the Morgan table; using stratified sampling technique. Data collection instruments were both primary and secondary, which included questionnaires, interview guides, and documentary review, and a purposive sampling technique was used. Project Sustainability shows that a unit increase on Hotel_Climate_Support causes a deficit on Project Sustainability which shows a deficit in the study. Innovation is a contributor to Project Sustainability. The study presents rich insights regarding innovation and has been generalized into one theoretical setup, design, and conceptualizations, the methodological limitation of using two Hotels, limits the customer Climate Support and to overcome in future research should be done using more than two theories.
\end{abstract}

Keywords:Revenue Collection, Hospitality Industry, Innovation and Project and Sustainability

\section{Introduction}

Globally, innovation plays an overarching role in a changing world of intense global competitiveness, along with fast-changing markets and technologies in projects that have been an overriding role to Project Sustainability (Politis, 2005). The significance of innovation on project sustainability has boosted institutional innovation and sustainability in products, services, systems, and processes that are regarded as a major characteristic in long-term institutional survival and success (Mathiesen\&

Einarsen, 2004). Companies' leaders have to be conscious about the nexus of sustainability in a wider context than seeking marketplace and advantage against competitors, companies and firms should be more concerned about the quality, values, and lasting of their products and services (Mirvis et al, 2010). The manufacturers in China have developed competitive advantages beyond cheap labor and large scale production. China's wind turbine and solar photovoltaic industry, motorcycle industry, and IT equipment industry point to "architectural innovation", whereby Chinese manufacturers modularized the integral designs of Japanese and Western companies (Heilman et al., 2015).

In Rwanda, according to a study done by the (World Bank 2018), Innovation and Project Sustainability requires the sophistication of firms and farmers, in improving capability to employ extension services to facilitate technological transfers to enterprises. Integrated support programs in support of organization to improve their management and internal capabilities are especially well suited in this regard. The government has already taken important steps to raise the innovation of firms and the bureaucracy. The creation of the National Industrial Research and Development Agency (NIRDA), National Commission of Science and Technology (NCST), and a few other organizations are key drivers in consolidating the initiatives of these organizations to ensure effective coordination of the National Institute of Statistics. This helps institutions 
and firms to identify where to invest scarce resources and to indicate clear roles for how these organizations could collaborate to improve the system.

The hospitality industry is regarded as a catalyst for economic growth and development in Rwanda. The sector employs over 50,000 youths, contributes to GDP growth, and promotes community development activities. The hospitality sector is the critical pillar in the tourism industry that provides lodging and value-added facilities to clients. It is believed that most sectors of the economy depend on the tourism industry and its contribution to over five billion Rwanda franc to G.D.P (Taoiseach, 2013).

\section{Review of Literature}

To (Jarvis et al., 2010), the sustainable development of hotels means that the development of the hospitality industry must be based on the tolerance of the ecological environment, in line with local economic improvement and principles, reducing the generation and emission of waste and pollutants by increasing the production process of hotel products and reducing the damage to the environment (Han \&Yoon, 2015).

Hotel environments are essential to their drive, and its stakeholders in organizational environmental activities with comprehension of the leadership devices and workplace support these behaviors. Understanding the factors that can influence employees' workplace is significant in improving environmental sustainability in the hospitality industry.

The study by Wesselink et al. (2017) finds a significant positive relationship between leadership behavior and employee PEB. The managers of small hotels could benefit from the effects of sustainable practices by incorporating sustainable practices; hotel leaders may be able to make a positive contribution to local people's lives now and for the future. Hotel leaders will also need to consider public health, social justice, human rights, labor rights, equal opportunities, and maintaining and promoting socioeconomic factors, which all lead to sustainable practices (Sloan et al., 2015).

Empowerment points to employee involvement, high involvement management, participative and selfgovernance (Peters \&Waterman, 1982). To other scholars, empowerment means "inclusion and allowing personal initiative" in line with organizational goals (Forrester, 2000). Culture, on the other hand, tends to serve as the social glue that provides cohesiveness to the organization (Smirch, 2012).

An empowerment culture gives employees the feeling that they are doing something worth their time and effort. It is worthwhile as an extensive employees' scheme increases confidence leading to competence. The freedom to choose how to do their work involves the sense that tasks are proceeding and that they are accomplishing something and maximizes the organization's difference, which leads to self-determination (Sprietzer et al., 2012). Despite efforts by development partners and other stakeholders, hotel projects remain challenged in the attainment of development goals; the hospitality sector faces many challenges when integrating sustainable development practices which the hoteliers have more responsibilities than just achieving organizational goals. Even with concerted efforts, the situation remains worrying; challenges are triggered by competitiveness and lack of innovative ideas to adopt new approaches to improve customers' experience. Hoteliers are yet to see the significance of incorporating sustainable business techniques to improve its reputations and employee relations (Jones, Hillier, \&amp; Comfort, 2016). Yet, the hospitality sector faces many challenges when integrating sustainable development which the hoteliers have more responsibilities than just achieving organizational goals.

The culture of empowerment takes place within the context of a strict management agenda where power is given by employers rather than taken by employees (Wilkinson, 1998). Empowerment can only work when it's well thought out and entrenched within institutional values or culture. Organizations can help employees understand core values through communication, training, and integrating the core beliefs of all organizational action on sustainability activities (Cook, 2013).

Sustainable Development in Hotels is one of the major polluters of the environment in which they operate. Hoteliers of small hotels face many challenges when incorporating sustainable development. Hoteliers have a myriad of role to perform. They must ensure they consider their stakeholders' well-being, implement environmental management, and abide by the code of ethics and social responsibility. However the hoteliers have 
seen the benefits of integrating innovative and sustainable business strategies to improve corporate reputations and efficiency, as well as employee relations (Jones, Hillier, and Comfort, 2016).

The five sustainable practices/principles that businesses must demonstrate are transparency of their practices with their stakeholder, implementing social and their organization practices, taking precaution and being responsible for their operational activities, and demonstrating responsible corporate citizenship, which most hotels have considered in recent development (Sustainable Development Knowledge Platform, 1992).

The sustainable development of the hotel means that the development of the hospitality industry must be based on the tolerance of the ecological environment, in line with local economic development and ethics, reducing the generation and emission of waste and pollutants, promoting the production process of hotel products and reducing the damage to the environment (Jarvis et al., 2010, Boley and Uysal, 2013, Chou, 2014, Geerts, 2014, Fraj et al., 2015, Han and Yoon, 2015). The study by Wesselink et al. (2017) finds Personal Environment Behaviors play an essential role in the greening of private and public organizations and established a relevant positive correlation between responsible leadership behavior for the environment and autonomous and external environmental motivation of employees. Hotels climate emphasizes sustainability in the project considering the environmental benefits. The project design can be characterized as a strategic choice to actively focus on sustainability during the project design development (Abidin\&Muganda2007).

Value management and life cycle management are two methods available for use in the projects' design phase to improve their sustainable performance. The context of sustainability looks at value addition and the realization of benefits and meeting the needs of the current users and provides similar conditions to future users.

\section{Stakeholder Theory}

Over the last decades, the correspondence between market value maximization in companies and social welfare has been called into question (Piketty, 2014) from a classical economic standpoint. The time may be right for companies to jointly consider the creation of social value and the distribution of that social value among stakeholders. In this context, the role of multinationals is particularly important, not only because of the great impact of their activities on the world economy but also because they are possibly the firms that find themselves under the most pressure to obtain short-term economic results (Jensen, 2002).

Following Boatright (2014), we might consider that the complexity of a transnational firm, its multiple interrelated objectives, and the variability of its stockholders, produce a complex system where linear control over value maximization is practically impossible. Nevertheless, stakeholder-oriented firms have a long tradition in Europe, where not only has an orientation been adopted that considers all stakeholders concerning company aims, but we have the examples of large French firms, or the Spanish savings banks (San-Jose, Retolaza, \& Torres, 2014), where stakeholders have become incorporated within the companies' governance bodies. In other word, Stakeholder theory is relevant in achieving the influence innovation on project sustainability considering different players in the hospitality industry. That is, the stakeholder theory is used in this study to highlight how the interests and power of the players in the hospitality industry can influence change.

\section{Methodology \\ Design, Target, Sample, Tools}

The researcher adopted a descriptive research design. The target population of the research was 160 employees including project and product team and the sample size was 113 from the hotels: Serena and Marriott Hotels which are engaged in the hospitality industry in Rwanda. The population included the employees in the Hotel.

The study used both probability and non-probability sampling techniques to select study respondents. For this research, the clusters constituted the selected urban centers in Kigali City. Simple random sampling was employed to determine the respondents to participate in the study from each cluster. For non-probability, purposive sampling was used. The researcher framed a sample list of 100 people from the hotels' staff and 60 hotel managers. The selection criteria were such that staffs involved in the management of the hotel were eligible for the 
study. This was to ensure that the study respondents had adequate knowledge to respond to the questions. Scientific formulawas used to randomize and pick 160 names; they were informed about the administration of the questionnaire, the target population totaling 160 employees where the sample size was 160 . In this case, the researcher used the Morgan table as a procedure.

Table 1: Categories of respondents

\begin{tabular}{lccccc}
\hline \multicolumn{1}{c}{ Respondents } & $\begin{array}{c}\text { Popula } \\
\text { tion }\end{array}$ & $\begin{array}{c}\text { Percen } \\
\text { tage } \\
(\%)\end{array}$ & $\begin{array}{c}\text { Sample } \\
\text { size }\end{array}$ & $\begin{array}{c}\text { Percent } \\
\text { age } \\
(\%)\end{array}$ \\
\hline $\begin{array}{l}\text { Senior Management } \\
\text { Project and Product }\end{array}$ & 60 & 3.5 & 20 & 10.9 \\
development team & 96.5 & 94 & 89.1 \\
Total & 160 & 100.0 & 113 & 100 \\
\hline
\end{tabular}

Source: Researcher own design, 2020

\section{Results and Discussion}

\subsection{Demographic Characteristics of Respondents}

On average, the respondents were aged between (2439 years) which represents 28.3 percent. It can be concluded that the majority of employees specifically work in the Hotel related departments are young while aged employees are few. Younger employees (24-39 years) are highly employed and receive benefits from using good hospitality in Serena. The success may be attributed to the Hotel public sector experiences that prepared them to own and grow operation techniques in their department; at the hotel, this translates to achievement. Additionallythe old-aged employees are (4055years). Results show that when old aged employees (40 -55 years) are primarily familiar with traditional approaches of hotel management and hospitality than stages of using innovative ideas that could translate to competitive advantage. This is because they have had adequate training that would improve their skills as the younger employees have theoretical and practical knowledge in the hospitality management.

\subsection{Gender}

It is evident that men represented 63.8 percent and are the majority of the respondents. Women are the minority, with 36.2 percent, as shown in Table 2 . This is positive but is contrary to past research by ILO (2008) that noted men tend to operate many departments in the hotel tasks more than women. Results indicate there is a need for Gender balance in employment and training for all Gender types. See table below.

Table 2: Gender

\begin{tabular}{lll}
\hline Gender & Frequency & Percent \\
\hline & & \\
Male & 102 & 63.8 \\
Female & 58 & 36.2 \\
Total & 160 & 100.0 \\
\hline
\end{tabular}

Source: Primary Data (2020)

\subsection{Results for Model Summary}

In this Study, the imprecise nature of the responses is analyzed by a combined method that integrates the methodology of fuzzy sets with the technique of similarity to the ideal solution. This method has been applied in various fields like (1) business management (Kannan et al., 2014; Liao \& Kao, 2011; Zyoud et al., 2016); and (2) civil engineering and transport (Gumus, 2000); Wang \&Elhag, 2006); and hospitality.Zadeh (2012) is usually considered the father of the development of fuzzy logic. The origin of the theory is that many of the sets found in reality do not have clear and defined boundaries of the internally contained elements. In our case study, guests who are not very satisfied with each of the attributes included in the analysis can be better formulated with this type of logic. 
Table 3: Model Summary

\begin{tabular}{lrrrrr}
\hline Model & R & R Square & Adjusted R Square & $\begin{array}{c}\text { Std. The error of the } \\
\text { Estimate }\end{array}$ & Durbin-Watson \\
\hline 1 & $.603^{\mathrm{a}}$ & .363 & .298 & .16082 & 1.240
\end{tabular}

a. Predictors: (Constant), Innovation, Hotel Climate Suppor

b. Dependent Variable: Project Sustainability

Table 4: Results for Regression Model

a. Dependent Variable: Project Sustainability

\begin{tabular}{llrrrrr}
\hline Model & \multicolumn{2}{c}{$\begin{array}{c}\text { Unstandardized } \\
\text { Coefficients }\end{array}$} & $\begin{array}{c}\text { Standardized } \\
\text { Coefficients }\end{array}$ & T & Sig. \\
& \multicolumn{1}{c}{ B } & Std. Error & Beta & & \\
\hline (Constant) & 3.720 & .932 & & 3.990 & .000 \\
Innovation & .022 & .097 & .028 & .231 & .818 \\
Hotel Climate Support & -.231 & .175 & -.166 & -1.320 & .193 \\
\hline
\end{tabular}

Source: Primary Data (2020)

Findings in the table indicate that Hotel Climate Support is not significant ( $\operatorname{sig}=.193$, which is greater than $\mathrm{p}=0.05$, its $\mathrm{t}$-value $=-1.320$, is far less than 1.96; hence the null hypothesis is accepted, indicating that Hotel Climate Support for Innovative has no statistical significance on Project Sustainability, the results also show that a unit increase on Hotel Climate Support causes a decrease of -.231 to Project Sustainability. Similar studies indicate Climate Support for Innovative on Project Sustainability ensures good customer retention, and it supports proper management of hotels' wastes and other pollutants (Kleemeier et al.,2015).In this study, Literature agrees with the finding, as Ayusoet et al. (2012) assert that when communities are involved in project initiation and implementation, there is the assurance of innovation and sustainability subject to some conditions, unlike when they have no idea about the project or when it is imposed on them. This ensures the community's involvement in all aspects of the project lifecycle, and likely on Hotel Climate Support for Innovative on Project Sustainability.

In similar studies, Russia surveyed the hotel with 188 rooms, 58 of which are suites, and 122 employees take care of the facilities and guests. This hotel is one of the most famous in St. Petersburg. The 4-stars hotel was built in 2005 and is located in a new city district, not so well located to the historical attractions. The further finding has 251 rooms of different price categories and 160 employees work in the hotel. The 3-stars hotel is also found in the historical center, on the city's main avenue, close to the metro station. The hotel has 164 rooms and 97 employees.

\section{Conclusions}

Project Sustainability shows that a unit increase on Hotel Climate Support causes a deficit in Project Sustainability. The new mode of participation helps enhance the effectiveness, efficiency, and coverage of the project benefits. Innovation is a contributor to Project Sustainability. The study presents rich insights regarding innovation and has been generalized into one theoretical setup, design, and conceptualizations, the methodological limitation of using two Hotels, limits the customer Climate Support and to overcome in future research should be done using more than two theories. The findings reveal that; alternate hypotheses were accepted indicating that Hotel Climate Support for Innovative but has no statistical significanceand coverage of the project benefits

\section{Acknowledgments}

I wish to acknowledge Dr. CathlynnD'silva(PhD) for her contribution to this work from the beginning up to its completion. I extend my acknowledgement to 
the Serena and Marriott Hotelauthorities for their support and cooperation during this study.

\section{Reference}

[1] Acemoglu, D., and P., Restrepo. (2017). "Robots and Jobs: Evidence from US Labor Markets."Cambridge, MA:Working Study 23285, National Bureau of Economic Analysis.

[2] Adam Smith International. (2017). 'Investors'Perceptions and Constraints Faced by Exporting firms in Rwanda's Priority". Economic Sectors Final Report, Adam Smith International, London.

[3] Amin, M., and A.Mattoo (2000). "Human Capitaland the Changing Structure of the Indian Economy.Washington, DC: Policy Research Working Study 4576, World Bank.

[4] Andersen, M., B. Kett, and E. Von Uexkull. (2017).Corporate Tax Incentives and FDI in Developing Countries.” In 2017-2018 Global Investment Competitiveness Report: Foreign Investor Perspectives and Policy Implications, chi. 3, 73-99. Washington, DC: World Bank. https://doi .org/10 .1596/978-1-4648-11753_ch3.

[5] Armstrong, H. W., Kehrer, B., Wells, P. and Wood, A. M. (2001). The Evaluation of Community Economic Development nitiatives. Urban Studies, 39 (3), 457481

[6] Autor, D ., and D. Dorn (2013).“The Growth of Low-Skill Service Jobs and the Polarization of the US Labor Market." American Economic Review 103 (5), 1553-97.

[7] Agle, B. R., Donaldson, T., Freeman, R. E., Jensen,M. C., Mitchell, R. K., \& Wood, D. J.(2008). "Dialogue: toward superior stakeholder theory". Business Ethics Quarterly, 18(2), 153-190.

[8] Agle, B. R., Mitchell, R. K., \&Sonnenfeld, J. A.(1999)."Who matters to CEOs"?An investigation of stakeholder attributes and salience, corporate performance, and CEO values. Academy of Management Journal, 42(5), 507-525.

[9] Alcaraz, A. S., Rodenas, S. P. (2013).“The Spanish banks in face of the corporate social responsibilitystandards"RevistaBrasileira de Gestão de Negócios: previous analysis of the financial crisis. 15(49), 562-581.
[10] Arrow, K. J. (1984). "The economics of information" Harvard: Harvard University Press (Vol. 4).

[11] Asher, C. C., Mahoney, J. M., \& Mahoney, J. T.(2005)."Towards a property rights foundation for a stakeholder theory of the firm". Journal of Management and Governance, 9(1), 5-32.

[12] Balderstone, S.J. (1999a)."Examining the Theory of Constraints".Wellington: A Source of Operational and Financial Performance Improvement, Victoria University of Wellington.

[13] Bennis, W. (1997). '"Managing people is like herding cats", Soundview Executive Book Summaries, 19(3), 1-8.

[14] Becker, B (2015). "Public R\&D Policies and Private R\&D Investment": A Survey of the Empirical Evidence."Journal of Economic Surveys 29 (5), 917-42.

[15] Behuria, P (2012). "Centralising Rents and Dispersing Power While Pursuing Development"? Exploring the Strategic Uses of Military Firms in Rwanda.Review of African Political Economy 43 (150), 630-47.

[16] Bloom, N ., B. Eifert, A . Mahajan, D. McKenzie, andJ.Roberts (2013). "Does Management Matter"?Evidence from India." Quarterly Journal of Economics 128 (1), 1-51.

[17] Bloom, N ., A . Mahajan, D.McKenzie, and J.Roberts (2018). "Do Management Interventions Last"? Evidence from India." Cambridge, MA: NBER Working Study 24249, National Bureau of Economic Research.

[18] Bloom, N., and J . Van Reenen (2007). "Measuring and Explaining Management Practices across Firms and Countries." Quarterly Journal of Economics 122 (4), 1351408. — 2010. "Why Do Management Practices Differ across Firms and Countries?" Journal of Economic Perspectives 24 (1), 20324.

[19] BNR (National Bank of Rwanda 2016). Annual Financial Stability Report: June 2015-June 2016. Kigali: BNR.

[20] Boesso, G., \& Kumar, K. (2009). "Stakeholder prioritization and reporting: evidence from Italy and the US".Accounting Forum, 33(2), 162- 
175.http://dx.doi.org/10.1016/j.accfor.2008.07. 010

[21] Brown, L., LaFond, A., \& Macintyre, K.(2001)."Measuring capacity building.MEASURES valuation".Carolina Population Center, the University of North Carolina at Chapel Hill.

[22] Cernea, M. (1992).“Using knowledge from social science in development projects.Washington: World Bank Discussion Study.

[23] Chambers, R., Conway, G. R. (1991). "Sustainable rural livelihoods": practical concepts for the $21 \mathrm{st}$ century. Institute of development studies Discussion Study 296

[24] Chaskin (2001)."Building Community Capacity": A Definitional Framework and Case Studies from a Comprehensive Community Initiative. Urban Affairs Review 36 (3), 291323

[25] Casciaro, T., Piskorski, M. J. (2005)."Power imbalance, mutual dependence, and constraint absorption": a closer look at resource dependence theory. Administrative Science Quarterly, 50, 167-199.

[26] Campos, F ., M . Frese, M . Goldstein, L .Iacovone, H .Johnson, D .McKenzie, and M.Mensmann (2008). "Personal Initiative Training Leads to Remarkable Growth of Women-Owned Small Businesses in Togo." Washington, DC: Gender Innovation Lab Policy Brief 22, World Bank.

[27] Chavhan, R ., S. K.Mahajan, and J . Sarang (2012). "Supplier Development: Theories and Practices." IOSR Journal of Mechanical and Civil Engineering (IOSR-JMCE) 3 (3), 37-51.

[28] Cirera, X ., J . Frias, and J . Hill. (2017). "Innovation Policy Guide and Technology Adoption in Developing Countries". Washington, DC: UnpublishedWorld Bank.

[29] Cirera, X. and W.F.Maloney. (2017). "The Innovation Paradox: Developing-Country Capabilities and the Unrealized Promise of Technological Catch-Up". Washington, DC: World Bank.

[30] Cornell University, INSEAD, and WIPO (2013).Global Innovation Index (2013).The
Local Dynamics of Innovation. Ithaca, Fontainebleau, and Geneva

[31] Cruz, M ., M. Bussolo, and L. Iacovone. (2018).“'Organizing Knowledge to Compete: Impacts of Capacity Building Programs on Firm Organization.” Journal of International Economics 111 (March): 1-20.

[32] Dettmer, H.W. (1997). Goldratt's Theory of Constraints: A Systems Approach to Continuous Improvement.Milwaukee, WI: ASQC Quality Press.

[33] Dettmer, H.W. (1998). "Navigating Change": OrganisationalBehaviour and the Thinking Processes, APICS Constraints Management Symposium.

[34] Draman, R., and Holt, J.R. (2000)."Immunizing the Future": Strategic Competitiveness through TOC. St Paul, Minneapolis, MN: Joint Avraham Y. Goldratt Institute/ University (Executive) MBA Program Alliance Symposium (JEMBA).

[35] Diao, X J . Randriamamonjy, and J. Thurlow. (2017). "Urbanization and the Future of Economic Development in Rwanda." Washington, DC: International Food Policy Research Institute, Background Study for Future Drivers of Growth in Rwanda.

[36] Donaldson, T., \& Preston, L. E. (1995). "The stakeholder theory of the corporation": Concepts, evidence, and implications. Academy of Management Review, 20(1), 65-91.

[37] Dowling, G. R. (1995). "Corporate reputations"-The company's super brand. The Journal of Brand Management, 2 (6), 377385.http://dx.doi.org/10.1057/bm.1995.22

[38] EABC (East African Business Community) (2016)."East African Common Market Scorecard. EABC, Nairobi.

[39] Eichengreen, B ., and P . Gupta. (2010). "The Service Sector as India's Road to Economic Growth?'New Delhi: Working Study 249, India Council for Research on International Economic Relations (ICRIER).

[40] Enemark, S., Williamson, I. (2004). "Capacity building inland administration.- a conceptual approach" Survey Review, 37 (294), 639-650 
[41] Falk, I., \& Harrison, L. (1998). "Indicators of Social Capital: Social Capital as the product of local interactive learning processes". CRLRA Discussion Study series, D4

[42] Ford, M. (2015). "Rise of the Robots".New York: Technology and the Threat of a Jobless Future.Basic Books.

[43] Frey, C. B ., and M. Osborne (2016). "The Future of Employment": How Susceptible Are Jobs to Computerization?" Technological Forecasting and Social Change 114 (1): 25480 .

[44] Fiedler, L., \&Kirchgeorg, M. (2007). "The role concept in corporate branding and stakeholder management reconsidered": Are stakeholder groups different? Corporate Reputation Review, 10(3), 177-188. http://dx.doi.org/10.1057 /palgrave.crr.1550050
[45] Florea, R., \&Florea, R. (2013).“ Stakeholders interests analyze and harmonization - the starting point of strategic approach". Economy Transdisciplinarity Cognition, 16(1), 130-135.

[46] Guadalupe, M ., O. Kuzmina, and C. Thomas (2012). "Innovation and Foreign Ownership". American Economic Review 102 (7): 3594627.

[47] Kapil, N ., and A . Aridi . (2017). "Innovation Agencies: Takeaways from Emerging Innovation Systems .’Washington, DC: Unpublished Study, World Bank.

[48] Lemarchand, G . A ., and A . Tash, eds. (2015).Mapping Research and Innovation in the The Republic of Rwanda. GOàSPIN Country Profiles in Science, Technology, and Innovation Policy. Paris: United Nations Educational, Scientific, and Cultural Organization (UNESCO) vol. 4. 